\title{
School-Based Brazilian Librarianship: The Ruling Relations That Inform Its Professional Practice
}

\author{
Melissa P. Johnston \\ University of West Georgia \\ Carrollton, GA \\ USA \\ mjohnsto@westga.edu
}

\author{
Lucy Santos Green \\ Georgia Southern University \\ Statesboro, GA \\ USA \\ Igreen@georgiasouthern.edu
}

\begin{abstract}
The need to equip today's youth with complex information literacy and knowledge construction skills is a catalyst for change in the traditional practices of school librarians the world over. This necessary change led us to explore school library practices through a global lens. Creating innovative research partnerships with school librarians in other countries provides a space for inquiry that identifies barriers (as well as potential solutions to these barriers) to professional preparation of school librarians for the digital age. This research inquires "what are the similarities in the experiences and practices of school librarians across international boundaries in efforts to meet the needs of $21^{\text {st }}$ century learners?" and more specifically "how do ruling relations impact and shape the experiences and practices of school librarians in Brazil?" Institutional Ethnography methodology is utilized to gain insight into the actualities of professional work lives, while examining the ruling relations that impact the institution. This paper presents findings from phase two of a study on school librarianship, conducted in the fall of 2015 in the State of Pará, Northwest Brazil.
\end{abstract}

Keywords: leadership, teacher librarians, institutional ethnography, Brazil

\section{Introduction \& Research Purpose}

The need to equip today's youth with complex information literacy and knowledge construction skills is a catalyst for change in the traditional practices of teacher librarians the world over. This necessary change led us to explore school library practices through a global lens. Creating innovative research partnerships with teacher librarians in other countries provides a space for inquiry that identifies barriers, as well as potential solutions to those barriers, to professional preparation of teacher librarians for the digital age. 
School-based librarianship in Brazil has made strides in the expansion of its instructional role, yet continues to reflect the social and economic disparity visible between middle and upper class private schools and government--funded public schools, as well as Brazilian society at large. Although the field faces unique challenges related to culture, government structures and the history of Brazilian education, many of the issues confronted by school-based Brazilian librarians are quite similar to challenges faced by teacher librarians in other countries.

Research questions addressed by institutional ethnography are related to common problems and experiences (Given, 2008) and aim to explore problematic experiences characterized by underlying tensions and contradictions seemingly generated beyond the individuals involved (Campbell \& Gregor, 2004). The institutional ethnographer must take on the viewpoint of the people engaged in the problematic experience (Campbell \& Gregor, 2004) because only then is the researcher able to investigate the ruling relations of an institution and its effect on local experiences (Devault \& McCoy, 2006). In institutional ethnography the researcher "inquires, investigates, examines, and observes," but does not impose (Given, 2008, p. 434). This inquiry questions "what are the similarities in the experiences and practices of school librarians across international boundaries in efforts to meet the needs of $21^{\text {st }}$ century learners?" and more specifically "how do ruling relations impact and shape the experiences and practices of school librarians in Brazil?" This paper presents findings from phase two of a study on school librarianship, conducted in the fall of 2015 in the State of Pará, Northwest Brazil.

\section{Methodology}

Institutional Ethnography (IE), is a methodology for explaining and gaining insight into the actualities of professional work lives, while examining the ruling relations that impact the institution (Campbell \& Gregor, 2004; Leckie, Given, \& Lushman, 2010). Social researcher Dorothy E. Smith developed institutional ethnography as an inquiry framework that focuses on the day-to-day work life of individuals, describing how they choose to operate within their institutions, while examining the ruling relations that impact that institution (Campbell \& Gregor, 2004; Stooke, 2010b). It is a "way of seeing, from where we actually live, into the powers, processes, and relations that organize and determine the everyday context of that seeing" (Smith, 2005, p. 9). IE aims to capture how these activities are organized around a distinctive function such as law, education, or international development (Campbell \& Gregor, 2004). IE researchers attempt to explain problematic situations by investigating how people's actions are coordinated and how people's experiences are organized within an institution. The IE researcher learns by focusing on actual people, their work, and the conditions of their work (Given, 2008), beginning with "the experience of the individuals in a local setting, but aiming to go beyond what can be known at that local setting" (Campbell \& McGregor, 2004, p. 59).

IE research examines everyday experiences and activities in a local setting in order to explicate the translocal (outside) institutional processes and practices that shape and 
govern daily work (Campbell \& Gregor, 2004; DeVault \& McCoy, 2006; Smith, 2005). Smith (2005) calls these translocal forces ruling relations. Ruling relations are defined by institutional ethnography as unseen structures that shape and organize practice and coordinate the activities and actions of people in and across various and multiple settings (Campbell \& McGregor, 2004; DeVault \& McCoy, 2006). Institutional ethnography, begins with the experience of the individuals in a local setting, but aims to go beyond what can be known just at the local level to connecting work and issues across multiple sites, uncovering how institutional factors shape practice in sometimes unrecognized ways, thus providing information to foster change at the local level. IE provides a lens through which to examine these ruling relations; ruling relations that the participants themselves may not entirely be aware of that impact daily work (DeVault \& McCoy, 2006).

\section{Research Design}

IE studies are often developed in response to a vague, persistent concern about a situation and the people it affects (Stooke, 2010). In the context of this study, the concern is the practices of the teacher librarian in meeting the needs of $21^{\text {st }}$ century learners, and how these practices are shaped by institutional characteristics and culture. This research follows a two-phase model of institutional ethnography. Phase one starts with conducting and analyzing interviews, texts, and observations to determine further research questions and identify institutional process for further study (Campbell \& Gregor, 2004). In 2013 the researchers began phase one by observing and documenting the practices, or work, of school-based librarians in Brazil in order to develop understandings based on observations and exchanges with those that are directly involved (Green \& Johnston, 2015). This next phase of the research serves to further explore and understand how these ruling relations shape practice and the connections across the institution of teacher librarianship.

In IE research there is a sequence of steps to guide the researcher. First, a point of entry for the inquiry is identified, which for this study, was the previous relationships and contacts with school-based Brazilian librarians (Green \& Johnston, 2015). Next, institutional processes or elements that shape the situation are identified. In phase one of this research the themes of collaboration, literacy, instruction, the learning environment, and technology emerged. As themes were established, ruling relations such as legislation, governing boards, professional organizations, education, and administration were apparent in the work of the librarians. In this step, processes or elements are investigated to objectively describe how these shape the situation being studied (DeVault \& McCoy, 2002). Therefore, the interview questions for this research were based on study findings from phase one of this IE research conducted in Brazil during the summer of 2013 in order to investigate the processes and practices observed at that time (Green \& Johnston, 2015).

\section{Research Setting}


During the fall of 2015, the researchers spent two weeks in Pará, Northwest Brazil, conducting school site visits, and interviewing school-based librarians, instructional technologists, curriculum specialists and school administrators, individuals that offered the most learning opportunities for intense study due to their accessibility (Denzin \& Lincoln, 2008). Northwest Brazil serves as a geographical and cultural contrast to Southeast Brazil, the site of phase one of this study. It is also a more economically challenged region where much of the state government and human capital resources are centered at the state capitol, making them inaccessible or difficult to obtain by smaller cities. After communication with the state Minister of Education, we selected to focus our observations and visits on the town of Santarèm.

Santarèm, the third most populous city in Pará, is considered the urban, financial, cultural, and commercial center of West Pará. Even so, at approximately 290,000 inhabitants, it is not a large city by global standards. It is located in a beautiful region, nestled where the Amazon River and the Tapajós River converge, flowing side by side yet never mixing. One of the oldest cities in the Amazonian region, it is often referred to as the "Pearl of Tapajós," and its citizens often brag on the gorgeous riverbed beaches once referred to by English royalty as the Brazilian Caribbean. Despite these characteristics, again, it must be emphasized that Santarem is a larger urban center relative to other areas of Pará and not the large, urban metropolitan cities found in the Southeast.

Due to its size, geographical location, proximity to a university, and the broad access granted by the ministry of education, we were able to select 20 schools from a list of almost one hundred institutions. These schools were selected in collaboration with a school district official who helped identify a purposive variety in student socioeconomic status, settings, grade levels, structure (public, private, charter) and condition of school libraries, selected for offering the most learning opportunities for intense study due to their accessibility and openness (Denzin \& Lincoln, 2008; DeVault \& McCoy, 2008).

\section{Data Collection}

In an IE inquiry, data collection techniques are mainly qualitative approaches, including interview, focus groups, participant observation, and textual analysis. This qualitative data is utilized to develop a description of what the participants do in their everyday work life. Much time is often spent on the collection of data from participants by encountering the actualities through observing or talking with those that are directly involved in order to understand the participants' experiences (DeVault \& McCoy, 2006; Given, 2008). Then, researchers, through examining the descriptions and the participants' stories, "can begin to identify some of the translocal, [or ruling] relations, discourses, and institutional work processes that are shaping the [participants'] everyday work" (DeVault \& McCoy, 2006, p. 21). The data collected and analyzed in this investigation came from the interactions and activities of subjects in the local setting, or the subjects whose experience is the problematic under investigation (Campbell \& McGregor, 2004). 
Because IE research is exploratory, universality and generalizability do not factor into sampling or research design. Rather, the analysis of problems in an institutional setting tends to describe and map nationally or internationally consistent social relations with local differences as variations in generalized ruling practices of that institution (DeVault \& McCoy, 2006; Smith, 2005). IE has been adopted in a variety of professional and human service disciplines, but it is not widely applied in LIS research. Since IE is quite useful in highlighting work that may not be recognized in official institutional discourse, it is especially beneficial to school-based librarianship where work entails both physical and intellectual activities within and beyond traditional learning contexts like classrooms. Applying IE to school-based librarianship helps to develop a map of, as well as pinpoint potential solutions to, the challenges endemic in the field.

\section{Interviews}

Interviewing is an important element of institutional ethnographic research, and has been described as "talking with people" (DeVault \& McCoy, 2006, p. 18). There are no standard sets of questions used for IE interviews. Instead, questions are based partly on what is learned from previous informal conversations and partly on the researcher's accrued knowledge of the social relations constituting the problematic under investigation (DeVault \& McCoy, 2006), therefore questions were based on the previous 2013 research (Green \& Johnston, 2015).

The researchers conducted approximately 67 structured and semi-structured interviews with school-based Brazilian librarians, principals, instructional technologist, and classroom teachers at 20 separate school site visits, accompanied by a community leader and former school teacher. At each site, the community leader presented an introductory letter generated by the Pará Ministry of Education. It is important to note that while the letter requested school access, it did not require that the researchers be granted that access. If the school accepted the letter, then the researchers would be escorted to the school principal or instructional specialist. This would be the first interview conducted.

All of these informal semi-structured interviews were recorded using a digital audio recorder and thorough researcher notes. The researchers recorded over 50 hours of visits to the 20 public, private, and charter K-12 schools, preserving Brazilian educator reflections on professional preparation for school-based librarianship, school library activities, professional challenges, and the roles of school-based librarians in $21^{\text {st }}$ century Northwest Brazil. One of the researchers, a native Portuguese speaker, also recorded clarifying questions and reviewed interview transcripts with interviewees, allowing for member-checking of information recorded after each interview (Lincoln \& Guba, 1985). Interviewees were also given the option of writing down their email addresses for the researchers so that research findings might be shared.

\section{Observations}


The researchers also were allowed to visit the school library (or where the library was "housed") and the computer lab at each site. Utilizing an observation protocol adapted from Johnston (2013), researchers recorded observations and verbal exchanges concerning school library policies, procedures, and practices; the school library collection and facility; types of activities taking place in the library; technology usage; and the roles of teachers and the librarian. Additionally, digital photographs were taken at each site to enrich and clarify the observations.

\section{Data Analysis}

All verbal and textual data collected was transcribed and entered into a spreadsheet for translation and coding. The researchers utilized inductive qualitative content analysis to analyze interview transcripts, notes from informal conversations, photos, the observation questionnaires, and any institutional materials that were provided (Glaser, 1965; Zhang \& Wildemuth, 2009). During this process, the researchers coded the data according to the themes that emerged from the first study, which were: a) collaboration, b) information literacy, c) instruction, d) technology integration and e) learning environment.

Ethnographic researchers who utilize fieldwork and content analysis encounter advantages and challenges. An advantage of IE is that the methods used to gather data allow for direct access to the required information, but a challenge is that these methods can only reveal the content that interviewees choose to share during the fieldwork. IE research is used to explore problems at a particular location therefore comparisons to a larger populations are not possible in this type of research design; the conclusions are limited to the immediate problem under this investigation.

\section{Findings}

This report of the findings focuses on the "ruling relations" that impact school library professional practice in Brazilian K-12 schools in the digital age, specifically the differences in public versus private, the school "librarian," facilities, and technology. As data was coded by themes from the first phase of this research, the ruling relations such as legislation, governing boards, professional organizations, education, and administration were apparent in each theme, and therefore the work of the librarians. In this phase of the research we begin to understand and explain how institutional factors shape practice in sometimes unrecognized ways across the institution of teacher librarianship.

\section{Ruling Relations: The School-Based Librarian}

Each school visited had its version of a school library and an individual fulfilling the functions of the school-based librarian. While in other areas of Brazil the researchers found most school-based librarians to be licensed librarians and not certified teachers, the opposite occurred in Santarém. Of the 20 schools visited, only one contained a licensed librarian. The rest of the school library spaces were operated by certified teachers, many of who were "repurposed" or reassigned to the library due to health issues. Since 2013, the federal government has begun to enforce its "every school a 
library, every school a librarian" mandate. It does so by requiring that libraries be run and maintained by licensed librarians. These individuals carry a license with photo on their persons at all times.

Even though Santarém has several institutions of higher education, the only university in the state that offers the library degree is the Universidade Federal de Pará, located at the state capitol, Belém. We were told over and over that schools would like to hire a licensed librarian, but finding one who is willing to relocate to Santarém is a severe challenge. The relocation issue is further aggravated by the fact that most schools cannot offer a licensed librarian full-time work (during all school sessions - many offered morning, afternoon and evening). While in Belém, a librarian might be able to supplement his or her income with work at a public library or other institution, these additional positions were harder to come by in Santarém. In fact, the one licensed librarian we interviewed explained that her acceptance of the school-based position was contingent upon a matching offer from the downtown public library.

The public schools visited attempted to address this human capital challenge by first renaming libraries, referring to these as "reading rooms," "teacher lounges," and "classrooms." Once the space was renamed, the requirement to staff it with a licensed librarian no longer applied. Then, the school system implemented a competitive application process for the library position, requiring that all interested employees submit a plan for a library program that supports content learning and promotes reading. Even though probationary teachers are still placed in school libraries as we observed in the Southeast, the difference is that in Santarém, we observed teachers who wanted to work in the school library.

Of the private schools we visited, one housed a licensed librarian (described earlier), one a teacher who was completing her library studies (partially funded by the school), and one school was in the process of hiring a licensed librarian from Belém. In the case of this third school, the principal explained that they had received a visit from the state's ministry of education who fined the school for running a library without a licensed individual. The school was given a set amount of time to properly staff the space. The director hinted that this visit seemed targeted: "Why us? Visit any of the government [public] schools, and you will not find a librarian. It is hard not to feel we were targeted on purpose." We could not confirm this viewpoint, and instead defer to the public schools' practice of renaming library spaces, thus taking advantage of a legal loophole.

As noted in the 2013 study, "the unique Brazilian approach to division of labor" impacted all school libraries that we visited. Duties North Americans associate with school librarianship, specifically in reference to technology integration and digital learning, are assigned to the instructional technologist (explained further in the subsequent section). The outsourcing of reading enrichment and literacy development was not observed as frequently in Santarém because the overwhelming majority of libraries we visited were staffed by former classroom teachers who presented literacy development plans as part 
of their application process. Interestingly, the one instance we observed this instructional division was at the large private school that staffed a licensed librarian. In her library, she oversaw an instructional technology teacher and a probationary teacher assigned to the space. She explained the division: "I am so blessed to have them here with me. She's [points to probationary teacher] an experienced teacher so when students and teachers need help with lessons or learning activities, she can help them. When they need help with technology, she [points to instructional technologist] can help them. Because they are here, I can concentrate on curating and developing the collection, which is extremely large."

\section{Ruling Relations and the School Library: Space and Access}

Once again we observed how the strong federal legislative push for literacy development impacted student access to materials in both the school library and classrooms through the large presence of didactic materials. Although the quantity varied in each school, we recorded instances at almost every public school site where these books were kept in original plastic packaging, stacked against a wall, blocking shelving or access to entire sections of the library. This occurred because 1) the books could only be used or handed out to if there were enough books for each student and 2) there were never enough books for each student because the number of books sent was based on the previous year's enrollment. There were a few public school libraries that contained larger collections, many of the books the result of university programs and donations. One school solicited book donations from each family at the end of the school year and amassed quite a collection in this manner. This dependence on government funding and materials did not impact the private schools (all of which had stronger and larger collections).

Student access to the library varied widely across all locations. While originally this seemed to be the result of building leadership, we discovered that local school district policies were the strongest determiners of student access. As an example, construction and building repairs were being conducted throughout the school district. Unfortunately, with funds for payment of construction workers delayed over and over again, many libraries suffered from disrepair. Some had air conditioning units that could not be turned on because the windows had no glass panes. Other spaces suffered from the exact opposite: closed windows and no AC - a situation that damaged computers at several locations. In three locations visited, schools were allotted new classrooms but had yet to see these built. Little by little, classes took over the computer lab, teacher's' lounge and the library. In one case, the librarian took baskets of books around to individual classrooms for the students to read. Maintenance and repair of buildings severely impacted student access also because of the way the local school district policy determined staffing. Some schools were allocated a librarian for part of a school day (a full day is made up of a morning session, an afternoon session and an evening session). Some schools saw the librarian every other day. Others still never received a library position and simply kept the library closed and the books stocked. In the most severe instance, a public school principal took us to a room that was basically an outdoor 
courtyard: "When it rains, the rain gets everywhere. So little by little we've been moving the books into the classrooms. I try to come in here and organize it as much as possible." This school did not have a librarian. The school principal actually functioned as the librarian for the school in her rare, spare moments.

\section{Ruling Relations and Technology}

Disparity between public and private schools was extremely apparent in the technology available in the buildings. While private schools had access to state-of-the-art computer labs and wireless internet access, most public school-based librarians described their technology as outdated and unusable. In fact, none of the public school libraries had online catalogs. Most kept check in and check out records of some sort in a handwritten ledger. Some schools used check in and check out photo ID cards created using card stock. The access to wireless internet also varied widely - again, a result of school district policy and the desire or lack thereof by administration to enforce those policies. While wireless internet was present at every school, the local government complained that students were using too much bandwidth, demanding that administrators remove student access to wireless internet. In buildings where administrators chose to enforce the policy, only the school secretary had access to the internet password. Other administrators encouraged a bring your own device (BYOD) system and allowed schoolwide internet access, claiming that the policy was based on greed and mismanagement of funds by the government. One school principal pointed out that it was impossible to keep the password a secret, and so he would not waste time trying.

It's important to note that many of the public schools had computer labs with functioning computers. These were not the newest models, but were comparable to what might be seen at a North American school. However, a bottleneck similar to the one that impacted construction also impacted computer maintenance. Many of the schools were allotted an instructional technologist - the individual responsible for technology and technology integration in the schools. Technology is not, therefore, the responsibility of the librarian, a division of labor ruling relation that has remained consistent in our visits across Brazil. Although one might expect that this individual would be responsible for maintenance of computers, her or she had to submit maintenance requests to the district. Maintenance requests would go unanswered and many computers sat unused. Several of the ITs shared with us that they knew how to fix the computers but were expressly forbidden from doing so.

The district attempted to foster a strong instructional technology program. We witnessed students learning to code, developing multimedia projects, engaging in research, using Scratch, and developing comic strips online. Many of the instructional technologists submitted these student projects to a large technology fair and competition hosted by the district. Similar to the school-based library positions, the instructional technologists even probationary teachers - must apply and complete a lengthy proposal in order to be considered for the position. Also, like the school library, if a school did not have an instructional technologist, the computer lab remained closed. 


\section{Conclusion}

The identification of the ruling relations provides important information for practicing teacher librarians by making power structures visible, identifying both formal and informal barriers to the profession. This 'making the invisible visible' leads to the collection of information needed to develop solutions and programs that strengthen school library programs. Although institutional ethnography research does not identify these solutions, it does provide an understanding of the impact of ruling regulations on practice and negotiate the these power structures to ultimately achieve the goals of school librarianship, to "producing successful learners skilled in multiple literacies" (AASL, 2009, 5).

\section{References}

American Association of School Librarians. (2009). Empowering learners: Guidelines for school library media programs. Chicago, IL: ALA.

Campbell, M., \& Gregor, F. (2004). Mapping social relations: A primer in doing institutional ethnography. Aurora, ON: Garamond Press.

Campello et al. (2011). Parâmetros para bibliotecas escolares Brasileiras: Fundamentos de sua elaboração. Informação e Sociedade: Estudos, 21(2), 105-120.

Creswell, J. W. (2013). Qualitative inquiry and research design: Choosing among five approaches. Thousand Oaks, CA: Sage.

DeVault, M. L., \& McCoy, L. (2006). Institutional ethnography: Using interviews to investigate ruling relations. In D.E. Smith (Ed.) Institutional ethnography as practice (pp. 15-44). New York, NY: Rowman and Littlefield.

Denzin, N. K., \& Lincoln, Y. S. (2008). Strategies of qualitative inquiry (3rd ed.). Thousand Oaks, CA: Sage.

Given, L. M. (Ed.). (2008). The SAGE encyclopedia of qualitative research methods. Thousand Oaks, CA: SAGE Publications, Inc.

Glaser, B. G. (1965). The constant comparative method of qualitative analysis. Social Problems, 12(4), 436-445.

Green, L. S., \& Johnston, M. P. (2015). Global perspectives: Exploring Brazilian schoolbased librarianship through institutional ethnography. School Libraries Worldwide, 21(1), 1-18.

Johnston, M. P. (2013). Investigating an international exchange of best practices between German and American school-based librarians. School Libraries Worldwide, 19(1).

Leckie, G. J., Given, L. M., \& Buschman, J. E. (Eds). (2010). Critical theory for library and information science: Exploring the social from across the discipline. Santa Barbara, CA: Libraries Unlimited.

Lincoln, Y. S., \& Guba, E. G. (1985). Naturalistic inquiry. Beverly Hills, CA: Sage Publications.

Smith, Dorothy E. 2005. Institutional ethnography: A sociology for people. Lanham, MD: AltaMira. 
Stooke, Rosamund K. 2010a. Institutional ethnography. In Theories of Information Behavior, ed. Dorothy E. Smith. Milford, NJ: Information Today.

Zhang, Y., \& Wildemuth, B. M. (2009). Qualitative analysis of content. In B. M. Wildemuth Applications of social science research to methods to question in library and information science. Englewood, CO: Libraries Unlimited. 